\title{
Immunization with a DNA vaccine encoding Toxoplasma gondii Superoxide dismutase (TgSOD) induces partial immune protection against acute toxoplasmosis in $\mathrm{BALB} / \mathrm{c}$ mice
}

\author{
Yuan Liu ${ }^{1 \dagger}$, Aiping Cao ${ }^{1,3+}$, Yawen $\mathrm{Li}^{1}$, Xun $\mathrm{Li}^{2}$, Hua Cong ${ }^{1}$, Shenyi He ${ }^{1}$ and Huaiyu Zhou ${ }^{1 *}$
}

\begin{abstract}
Background: Toxoplasma gondii (T. gondii) is an obligate intracellular protozoan parasite that infects all warmblooded animals including humans and causes toxoplasmosis. An effective vaccine could be an ideal choice for preventing and controlling toxoplasmosis. T. gondii Superoxide dismutase (TgSOD) might participate in affecting the intracellular growth of both bradyzoite and tachyzoite forms. In the present study, the TgSOD gene was used to construct a DNA vaccine (pEGFP-SOD).

Methods: TgSOD gene was amplified and inserted into eukaryotic vector PEGFP-C1 and formed the DNA vaccine pEGFP-SOD. Then the BALB/C mice were immunized intramuscularly with the DNA vaccine and those injected with pEGFP-C1, PBS or nothing were treated as controls. Four weeks after the last immunization, all mouse groups followed by challenging intraperitoneally with tachyzoites of T. gondii ME49 strain.

Results: Results showed higher levels of total lgG, IgG2a in the sera and interferon gamma (IFN- $\gamma$ ) in the splenocytes from pEGFP-SOD inoculated mice than those unvaccinated, or inoculated with either empty plasmid vector or PBS. The proportions of $\mathrm{CD}^{+} \mathrm{T}$ cells and CD8 ${ }^{+} \mathrm{T}$ cells in the spleen from pEGFP-SOD inoculated mice were significantly $(p<0.05)$ increased compared to control groups. In addition, the survival time of mice immunized with pEGFP-SOD was significantly prolonged as compared to the controls $(p<0.05)$ although all the mice died.

Conclusion: The present study revealed that the DNA vaccine triggered strong humoral and cellular immune responses, and aroused partial protective immunity against acute T. gondii infection in BALB/C mice. The collective data suggests the SOD may be a potential vaccine candidate for further development.
\end{abstract}

Keywords: Toxoplasma gondii, ME49 strain, Superoxide dismutase, DNA vaccine, BALB/c mice

\section{Background}

Toxoplasma gondii (T. gondii), one of the most successful parasites, is an obligate intracellular Apicomplexa protozoan, that can infect a wide variety of hosts including humans, livestock, and marine mammals and causes toxoplasmosis $[1,2]$. T. gondii infection in immunocompetent

\footnotetext{
* Correspondence: zhouhy@sdu.edu.cn

${ }^{\dagger}$ Equal contributors

'Department of Parasitology, School of Medicine, Shandong University, Jinan, Shandong Province, People's Republic of China

Full list of author information is available at the end of the article
}

individuals is clinically asymptomatic. However, toxoplasmosis occurred in immunocompromised individuals like those who are suffering from untreated HIV/AIDS is devastating [3]. Additionally, T. gondii infection not only causes abortions, stillbirths, and neonatal deaths in pregnant and lying-in women [4], but also leads to considerable economic losses in livestock, especially in sheep and goats $[5,6]$. To make matters worse, humans are commonly infected by ingestion of raw or partly cooked meat containing T. gondii viable tissue cysts or by consumption of contaminated food and water with T. gondii 
oocysts [7, 8]. Despite several available chemical drugs, they are not absolutely safe with toxicities and have limited efficacy. In consideration of the serious impact of toxoplasmosis on the public health and economy, developing an effective vaccine against toxoplasmosis is of vital importance $[9,10]$.

Up to present, vaccines against toxoplasmosis have experienced inactivated or attenuated vaccine, subunit vaccine, multi-antigenic cocktails vaccine [11], but only one licensed vaccine based on the live attenuated S48 strain has been put into use in sheep, rather than human $[12,13]$. DNA vaccine has been confirmed to elicit strong humoral and cellular immune responses and is more efficient and safer [14]. Thus, research priorities on prevention and treatment of toxoplasmosis could be shifted from chemical drugs, attenuated vaccine and subunit vaccine to DNA vaccines. In recent years, enormous achievements have been made on candidate antigens of DNA vaccines against toxoplasmosis [15].

Superoxide dismutase (SOD) is a major enzyme existing in a wide range of organisms, including animals, plants and microorganisms. SOD is mainly involved in the process of metabolizing $\mathrm{O}^{2-}$ in case of cell damage, namely, eliminating $\mathrm{O}^{2-}$ through conversing extra superoxide $\left(\mathrm{O}^{2-}\right)$ anion into hydrogen peroxide and oxygen $[16,17]$. This function of protecting cells from oxidative damages enables that SOD could be a potential research target in medicine, food industry and agriculture. Moreover, in $T$. gondii, several studies have shown that SOD might participate in affecting the intracellular growth of both bradyzoite and tachyzoite forms [18]. In our previous study, SOD gene was verified to have low sequence variation among ten examined isolates (RH, GT1, PTG, Prugniaud, CTG, TgCgCa1, MAS, TgCatBr5, TgCatBr64 and TgTouca), suggesting that SOD might be a potential vaccine candidate against T. gondii [19].

In this context, a DNA vaccine encoding Superoxide dismutase of $T$. gondii (TgSOD) was constructed, and then the murine immune responses and protection against challenge infection with the $T$. gondii ME49 strain were investigated.

\section{Methods}

\section{Ethical statement}

All animal care procedures were conducted in strict accordance with the Animal Ethics Procedures and Guidelines of the People's Republic of China. The study was approved by the Institutional Animal Care and Use Committee of Shandong University under Contract LL2015-02, and all possible efforts were made to minimize distress on animals.

\section{Animals}

Female BALB/c mice (6 weeks, $20+/-2$ g body weight) were obtained from the Animal Centre of Shandong University (Jinan, China). All mice were raised under specific-pathogen-free conditions and fed with basal diet and water ad libitum. The infected mice were closely monitored twice daily for loss of appetite, dehydration, watery diarrhea, ruffled fur, lethargy and hunched posture. If obvious sufferings were observed, the mice were euthanized immediately by ether inhalation.

\section{Parasites and soluble tachyzoite antigen preparation}

ME49 strain of T. gondii was kindly provided by Professor Quan Liu, Department of Parasitology, Military Veterinary Institute, Academy of Military Medical Sciences, China. The parasite was grown in human foreskin fibroblast (HFF) cells and maintained in complete medium supplemented with $10 \%$ fetal calf serum, $25 \mu \mathrm{g} / \mathrm{ml}$ gentamycine and $2 \mathrm{mM}$ glutamin at $37{ }^{\circ} \mathrm{C}, 5 \% \mathrm{CO}_{2}$. Soluble tachyzoite antigens (STAg) were prepared from the tachyzoites of ME49 strain with the aid of Ultrasonic disintegrator as previously described [20].

\section{Construction of recombinant pEGFP-SOD plasmid}

To construct the plasmid expressing recombinant SOD, the SOD gene was amplified by polymerase chain reaction (PCR) from genomic DNA of $T$. gondii tachyzoites of ME49 strain with one pair of primers: $5^{\prime}-\mathrm{CCC} A A$ GCTTATGGTATTCACTTTGCCCCCGCT-3' (forward) and 5' - CGGGATCCTCATTTCAAGGCATTCTCCAAG3' (reverse) containing Hind III and BamH I sequences (italicized). The amplification reaction was performed under the following program: initial denaturation at $94{ }^{\circ} \mathrm{C}$ for $3 \mathrm{~min}, 30$ cycles of denaturation at $94{ }^{\circ} \mathrm{C}$ for $30 \mathrm{~s}$, annealing at $63.6{ }^{\circ} \mathrm{C}$ for $1 \mathrm{~min}$ and extension at $72{ }^{\circ} \mathrm{C}$ for $1 \mathrm{~min}$, and final extension at $72{ }^{\circ} \mathrm{C}$ for $10 \mathrm{~min}$. Then the PCR product was inserted into the cloning vector pEASY-T1 (Trans Gen biotech Company, China). Subsequently through enzymes digesting and reclaiming, the SOD gene fragment was gained and subcloned into pEGFP-C1 (Clontech Company, USA). Finally, the recombinant plasmid was constructed and named as pEGFP-SOD and the schematic diagram of construction of DNA vaccine was shown in Fig. 1a.

\section{Expression of TgSOD in vitro}

To test the expression of recombinant plasmid in vitro, the recombinant plasmid pEGFP-SOD was transfected into HEK 293 T cells using the LipofectamineTM 2000 reagent (Invitrogen, USA) in 6-well tissue culture plates. The HEK 293 T cells transfected with the empty vector pEGFP-C1 was used as a negative control. Then the transfected cells were incubated at $37{ }^{\circ} \mathrm{C}, 5 \% \mathrm{CO}_{2}$ for 48 h. Those cells were observed under a fluorescence 

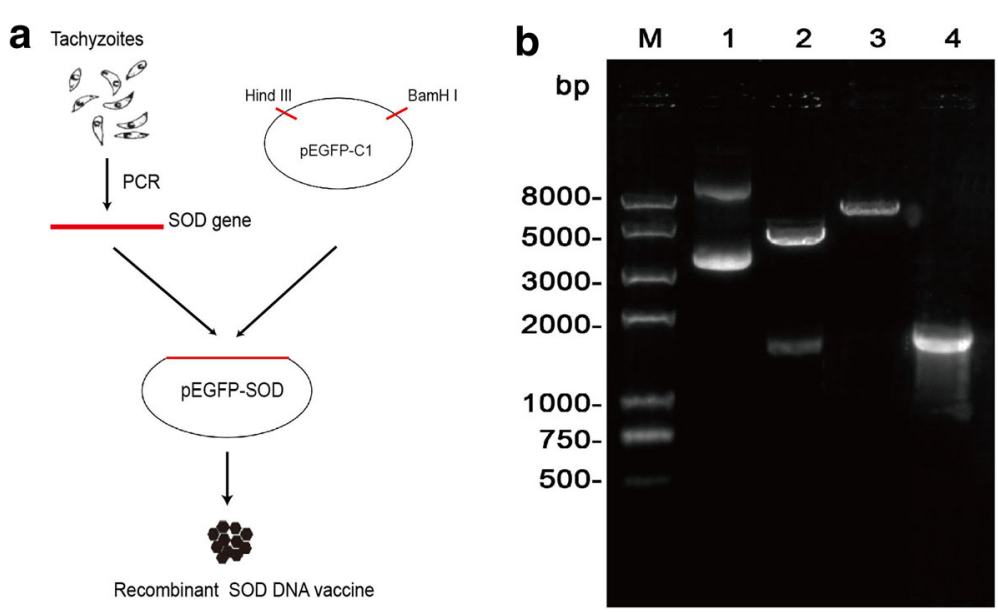

Fig. 1 Construction of recombinant plasmid DEGFP-SOD. a The schematic diagram of construction of DNA vaccine. $\mathbf{b}$ Identification of recombinant plasmid pEGFP-SOD using gel electrophoresis analysis. Lane 1, recombinant plasmid pEGFP-SOD; Lane 2, recombinant plasmid pEGFP-SOD was double digested by Hind III and BamH I enzymes; Lane 3, recombinant plasmid pEGFP-SOD was digested by BamH I enzyme; Lane 4, PCR products of SOD gene from pEGFP-SOD; M represents DNA molecular marker

microscope (Carl Zeiss, Germany) at 24 h post transfection. To prepare cell lysates for sodium dodecyl sulfategel electrophoresis (SDS-PAGE), cells were lysed with RIPA lysis buffer (Solarbio, China) containing $1 \mathrm{mM}$ protease inhibitor PMSF. Equal amount of proteins (30 $\mu \mathrm{g}$ per sample) were loaded onto a SDS-PAGE gel. The proteins were separated following a separation process for $1 \mathrm{~h}$ at $100 \mathrm{~V}$. Then the proteins were semidry transferred onto nitrocellulose (PVDF) membranes (Millipore, USA) at $80 \mathrm{~V}$ for $60 \mathrm{~min}$. Nonspecific binding sites were blocked with $5 \%$ skimmed milk powder in TBST (TBS plus 0.1\% Tween-20) for $2 \mathrm{~h}$ at room temperature (RT). The PVDF membranes were then incubated overnight at $4{ }^{\circ} \mathrm{C}$ with the sera of immunized mice on week 8 (diluted in 1:200) and GAPDH (Abbkine, USA; diluted in 1:2000) as internal reference. After being washed 3 times with TBST, the membranes were incubated with diluted secondary antibody (goat anti-mouse IgG-HRP, Proteintech, USA; 1:5000) for $2 \mathrm{~h}$ at RT. After through washing, the membrane was soaked in DAB Reagents (Millipore, USA) for signal development and was imaged using ChemiScope6300 (Clinx Science Instruments, China).

\section{DNA vaccine immunization in $B A L B / c$ mice and parasite challenge}

$\mathrm{BALB} / \mathrm{c}$ mice were randomly divided into four groups (12 mice per group). Before inoculation, plasmids were diluted and suspended in sterile phosphate buffered saline (PBS) to a final concentration of $1 \mu \mathrm{g} / \mu \mathrm{l}$. The $100 \mu \mathrm{l}$ pEGFP-SOD was used to immunize the mice for the experimental group. As negative controls, groups of mice were either untreated or injected with $100 \mu \mathrm{l}$ pEGFP-C1 or $100 \mu \mathrm{l}$ sterile PBS. All groups of mice were immunized in the same manner three times on days 1,15 and 29, respectively. Four weeks after the last immunization, 9 mice from each group were randomly chosen and put into infection experiments that each mouse was injected intraperitoneally with a dose of $1 \times 10^{3}$ tachyzoites of T. gondii ME49 strain. The rest mice (3 mice per group) were used for removing spleen under sodium pentobarbital anaesthesia and for further determination of cytokine production.

\section{Antibody determination assays}

Blood samples of mice in each group were collected by retro-orbital plexus puncture on days $0,14,28$ post immunization and four weeks after the final immunization (on day 56), then centrifuged at $5000 \times \mathrm{g}$ for $10 \mathrm{~min}$, and the sera isolated were stored at $-20{ }^{\circ} \mathrm{C}$ for further serological analysis. The levels of antigen-specific IgG and IgG subclasses in mouse sera were determined by enzyme-linked immunosorbent assays (ELISA). Briefly, STAg of ME49 strain was diluted to $12.5 \mu \mathrm{g} / \mathrm{ml}$ with coating buffer ( $\mathrm{pH}$ 9.6), and divided into 96-well enzyme panel with $50 \mu \mathrm{l}$ per well overnight at $4{ }^{\circ} \mathrm{C}$. Then, the plates were blocked with $5 \%$ bovine serum albumin (Solarbio, China) at $37{ }^{\circ} \mathrm{C}$ for $2 \mathrm{~h}$. The plates were washed three times with PBST, $50 \mu \mathrm{l}$ diluted mouse serum samples (serum: diluent $=1$ : 100) were added to the wells and incubated at $37^{\circ} \mathrm{C}$ for $1 \mathrm{~h}$ with gentle shaking. After washing three times with PBST, $100 \mu$ diluted enzyme-labeled second antibody (IgG-HRP, IgG1-HRP or IgG2a-HRP, 1:1000 dilution, Proteintech, USA) was added in each well, incubated at $37^{\circ} \mathrm{C}$ for $1 \mathrm{~h}$. The reaction was terminated by addition of $50 \mu$ of stop solution and the optical density was measured at $450 \mathrm{~nm}$ using an automated ELISA reader (Allsheng, China). All sera samples were run in triplicate. 


\section{Cytokine assays}

The splenocyte suspension was prepared from spleens of each group four weeks after the last immunization (on day 56). Splenocytes were cultured in vitro in the presence of concanavalin A (Con A; $5 \mu \mathrm{g} / \mathrm{mL}$; Sigma; positive control), STAg $(10 \mu \mathrm{g} / \mathrm{mL})$ or medium alone (negative control), respectively. Culture supernatants were collected at indicated time points. Interleukin-4 (IL-4) levels were measured at $24 \mathrm{~h}$ post stimulation, whereas Interleukin-10 (IL-10) and IFN- $\gamma$ were measured at $72 \mathrm{~h}$ and $96 \mathrm{~h}$ post stimulation, respectively. Cytokine level was determined by ELISA according to the manufacturer's instructions (Chengsen Trading Co., China). All assays were performed in triplicate.

\section{T cell subsets determination}

The percentages of $\mathrm{T}$ cell subsets $\mathrm{CD}^{+} \mathrm{T}$ cells and $\mathrm{CD}^{+} \mathrm{T}$ cells in spleen were determined by flow cytometry as previously mentioned [21]. The concentration of splenocyte suspension was adjusted to $1 \times 10^{7}$ cells $/ \mathrm{ml}$ in $100 \mu \mathrm{l}$ of PBS, and cell surface was stained with FITC-conjugated anti-mouse CD4 monoclonal antibody (mAb), Cy5.5-conjugated anti-mouse CD8 $\mathrm{mAb}$ (eBioscience) and PE-conjugated anti-mouse $\mathrm{CD} 3 \mathrm{mAb}$ for $0.5 \mathrm{~h}$ at $4{ }^{\circ} \mathrm{C}$ in the dark. Then the stained cells were washed with PBS for 3 times. All samples were collected and analyzed by a BD FACS Calibur (BD Biosciences, USA).

\section{Statistical analysis}

All data in the study, including results of the humoral responses, cytokine production and flow cytometric assays were processed and analyzed by one-way analysis of variance (ANOVA). The survival times for the vaccinated and control groups were checked by Kaplan-Meier method and compared with the log-rank test. The value of $p<0.05$ was considered to be statistically significant.

\section{Results}

\section{Identification of recombinant plasmid pEGFP-SOD}

SOD gene was subcloned into the eukaryotic expression vector pEGFP-C1 (pEGFP-SOD). In order to ensure the correct insert orientation, it was tested by PCR and endonuclease digestion. As shown in Fig. 1b, the SOD gene was a specific, approximate $1700 \mathrm{bp}$ in length on agarose gel, which was characterized by restriction endonuclease digestion as well as PCR amplification. Furthermore, DNA sequencing result showed that the SOD gene was 1706 bp with $100 \%$ identity to T. gondii ME49 strain (not shown here), suggesting that the recombinant plasmid pEGFP-SOD was correctly constructed.

\section{Identification of expression protein in vitro}

To test the expression of SOD from the constructed plasmid, the pEGFP-SOD was transfected into HEK $293 \mathrm{~T}$ cells. The specific green fluorescence was observed in the HEK $293 \mathrm{~T}$ cells transfected with the recombinant plasmid pEGFP-SOD (Fig. 2a, b), but not in the untrasfected cells (Fig. 2c), showing that recombinant was expressed efficiently in eukaryotic cells. Western blotting demonstrated that the expressed protein (lane 1) were reacted with anti-STAg mouse sera, whereas the control empty plasmid-transfected cells did not show any band (lane 2) upon incubation with the same antibody (Fig. $2 \mathrm{~d}$ ). The results showed that the protein of SOD was approximately $23 \mathrm{kDa}$, which was consistent to the expected molecular weight [18], and was recognized by anti-STAg mouse sera as antibody.

\section{Humoral immune responses}

To evaluate the levels of antibody in sera from the pEGFP-SOD group and the control groups, the total IgG was detected after three consecutive DNA immunizations (on weeks 0, 2, 4, 8). As shown in Fig. 3a, the level of IgG detected in pEGFP-SOD group was significantly higher $(p<0.05)$ than them of control groups. Moreover, with the increase of immunization frequency, the IgG level in serum from pEGFP-SOD group increased, it reached the peak in the fourth week after the final immunization.

IgG subtype, IgG1 and $\operatorname{IgG} 2 \alpha$, in each serum sample were measured by ELISA (on day 56). As presented in Fig. 3b, in immunized group, the levels of IgG1 and IgG2 $\alpha$ were obviously higher than that in control groups. The percentage of IgG2 $\alpha$ and IgG1 in the pEGFP-SOD group was the highest among all the groups with the dominance of IgG2 $\alpha$ over IgG1, whereas IgG1 level showed no significant difference, suggesting that pEGFPSOD could elicit a Th1 type cellular immune response.

\section{Cytokines production in vitro}

To determine the cytokine response in mice immunized with the vaccine pEGFP-SOD, the levels of IL-4, IL-10 and IFN $-\gamma$ that were secreted by spleen cells from all remaining immunized mice were measured by ELISA. The results in Table 1 showed that significantly higher level of IFN- $\gamma$ was observed in the pEGFP-SOD group compared with that in blank control, PBS- and pEGFPC1-immunized mice groups $(p<0.05)$. However, the levels of IL-4 and IL-10 among all of the study groups displayed no statistically differences.

\section{Analysis of $T$ cell subsets}

As demonstrated in Table 2, in experimental groups, the percentage of $\mathrm{CD}_{4}{ }^{+} \mathrm{T}$ cells showed somewhat statistical difference with that in control groups. However, between 

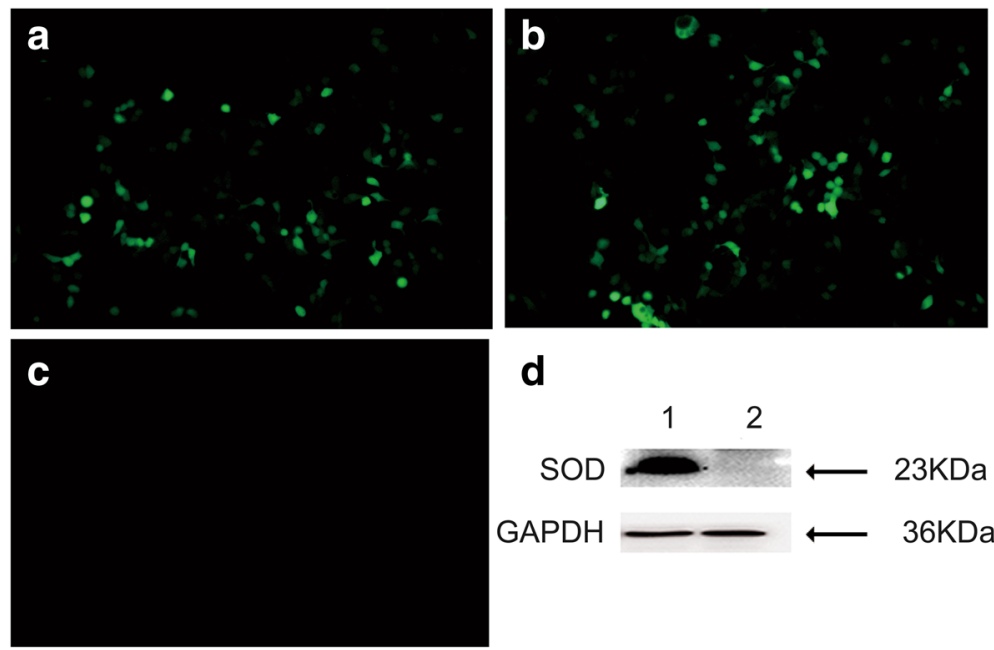

d

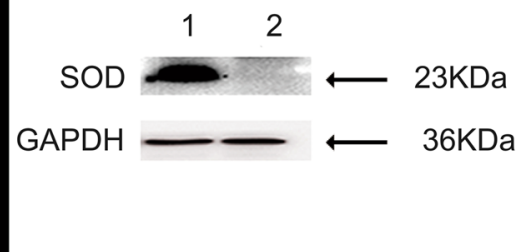

Fig. 2 Identification of TgSOD expression in vitro by fluorescence microscopic detection and Western blotting. Fluorescence microscopy images of TgSOD protein in (a) HEK 293 T cells that were transfected with pEGFP-SOD and (b) empty plasmid pEGFP-C1, and (c) non-transfected HEK 293 T cells; (d) Western blotting of pEGFP-SOD expressed in HEK 293 T cells (lane 1) probed with anti-STAg mouse sera as primary antibody and the protein of SOD is $23 \mathrm{KDa}$, whereas no band in the negative control cells with the empty plasmid pEGFP-C1 (lane 2) and GAPDH serves as a loading control

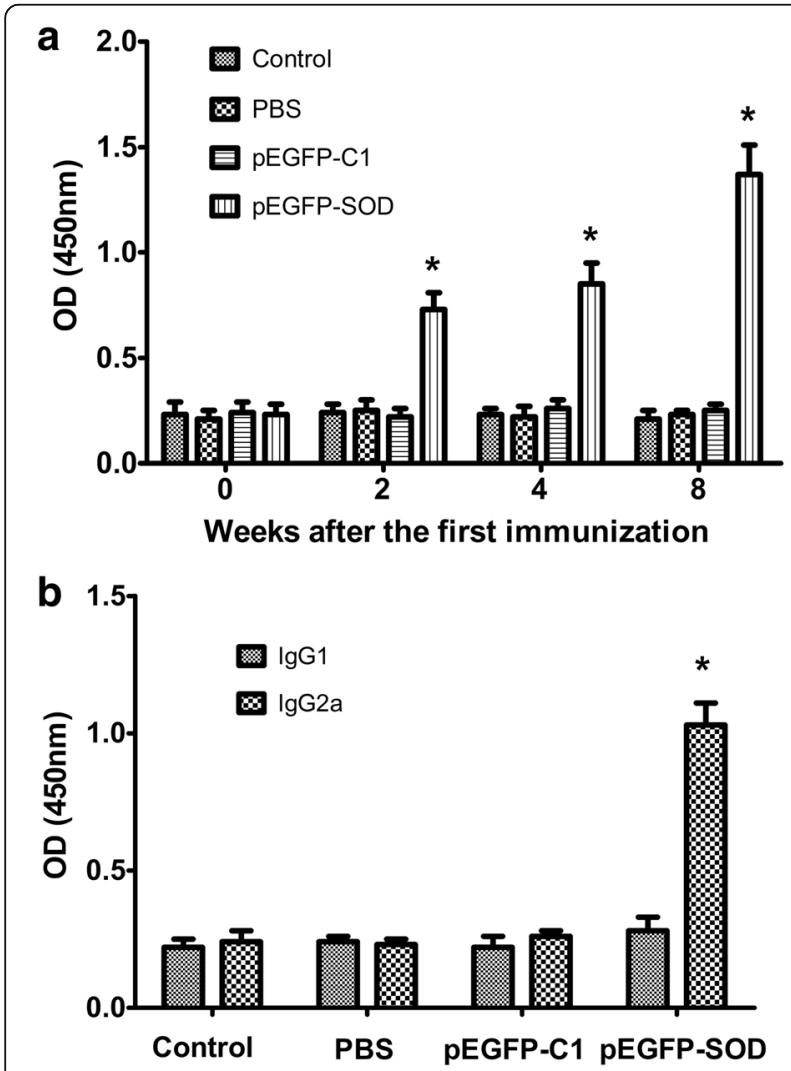

Fig. 3 Toxoplasma-specific antibody levels in the sera of immunized $\mathrm{BALB} / \mathrm{C}$ mice. The total lgG antibodies (a) in the collected serum samples of BALB/c mice immunized with pEGFP-SOD, pEGFP-C1, PBS and blank control on weeks $0,2,4,8$ were analyzed by ELISA. The levels of IgG1 and $\operatorname{lgG} 2 a$ (b) subtypes in the sera 28 days after the last immunization were determined by ELISA. The results are expressed as the means \pm SD from three independent experiments. $p<0.05$, pEGFP-SOD vs controls the experimental groups and the control groups, the obvious difference was found in the percentage of $\mathrm{CD} 8^{+} \mathrm{T}$ cells. As for $\mathrm{CD}^{+} \mathrm{T}$ cells, the pEGFP-SOD group showed the highest proportion $(p<0.05)$ four weeks after the last vaccination compared with the control groups (Blank control, PBS or pEGFP-C1 controls).

\section{Protection against challenge with $T$. gondii ME49 strain in} mice

The survival curves of the four mice groups after lethal challenge with the $T$. gondii ME49 strain were shown in Fig. 4 . The mice immunized with pEGFP-SOD had a significant increase in the survival days (median survival of 12.5 days) in comparison to the control mice unvaccinated, injected with PBS and pEGFP-C1 (median survival of 6,6 and 5 days respectively). Although all the immunized mice died within 17 days and all the control mice died within 4-8 days post challenge, the results

Table 1 Cytokine concentrations of splenocyte supernatants from the immunized BALB/c mice ( $n=3$ animals per group)

\begin{tabular}{llll}
\hline Groups & \multicolumn{3}{l}{ Production of cytokine $(\mathrm{pg} / \mathrm{mL})$} \\
\cline { 2 - 4 } & $\mathrm{IFN}-\gamma$ & $\mathrm{IL}-4$ & $\mathrm{IL}-10$ \\
\hline Blank control & $129.30 \pm 37.82$ & $22.45 \pm 7.22$ & $58.66 \pm 11.49$ \\
PBS & $119.36 \pm 34.77$ & $19.53 \pm 6.03$ & $61.31 \pm 15.40$ \\
pEGFP-C1 & $125.42 \pm 41.29$ & $20.65 \pm 8.63$ & $64.36 \pm 16.93$ \\
pEGFP-SOD & $3124.55 \pm 242.20^{*}$ & $24.96 \pm 11.48$ & $62.57 \pm 16.26$ \\
\hline
\end{tabular}

Cytokine production from splenocytes after stimulations in vitro. Results are expressed as means \pm SD from three independent experiments. IFN- $\gamma$ levels were measured at $96 \mathrm{~h}$ post stimulation; IL-10 and IL-4 were measured at $72 \mathrm{~h}$ and $24 \mathrm{~h}$ post stimulation, respectively

${ }^{*}$ Compared with blank control, PBS or pEGFP-C1 controls, $p<0.05$ 
Table 2 Percentages of $C D 4^{+} T$ cells and $C D 8^{+} T$ cells subsets in immunized BALB/c mice ( $n=3$ animals per group) by flow cytometry

\begin{tabular}{lll}
\hline Groups & $\mathrm{CD}^{+} \mathrm{CD}^{+} \mathrm{CD}^{-}(\%)$ & $\mathrm{CD}^{+} \mathrm{CD}^{+} \mathrm{CD}^{-}(\%)$ \\
\hline Blank control & $19.06 \pm 1.89$ & $14.13 \pm 1.34$ \\
PBS & $19.23 \pm 1.45$ & $13.08 \pm 1.18$ \\
pEGFP-C1 & $18.52 \pm 1.36$ & $14.05 \pm 1.02$ \\
pEGFP-SOD & $28.79 \pm 2.74^{*}$ & $30.94 \pm 3.27^{*}$
\end{tabular}

Results are expressed as the mean \pm SD ( $n=3$ animals per group) from three independent experiments. The splenocyte suspensions were detected by flow cytometry

*Compared with blank control, PBS or pEGFP-C1 controls, $p<0.05$

demonstrated that the immunized mice group with pEGFP-SOD had significantly prolonged survival rates as compared to the controls (Blank control, PBS and pEFGP-C1) $(p<0.05)$.

\section{Discussion}

T. gondii is one of the most important opportunistic Apicomplexan parasites, whereas no available drugs could effectively eliminate the pathogen from the host [1-3]. In recent studies, DNA-based vaccination has been considered to be a promising approach for the development of vaccine since it could protect animals and humans from viral, bacterial, and even intracellular parasitic infection, including intracellular parasites [22]. Owing to easy production and low cost of DNA vaccines, together with the fact that DNA vaccine could elicit long-lasting humoral and cellular immune responses [22, 23], the development of effective DNA vaccines has emerged as an active research field in the fight against toxoplasmosis [24]. And the use of a single antigen as DNA vaccines against experimental toxoplasmosis was

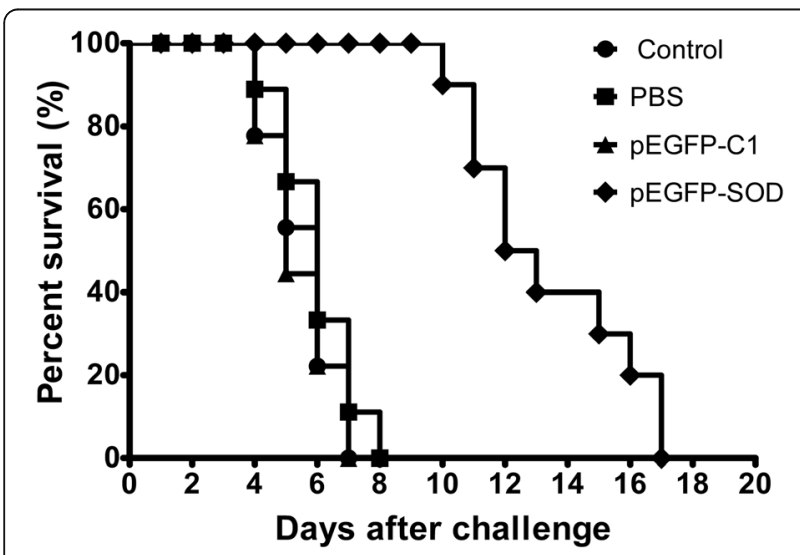

Fig. 4 Survival curves of mice in pEGFP-SOD and control groups, following challenge with T. gondii ME49 strain. Sunvival time was monitored daily after challenge with $1 \times 10^{3}$ live tachyzoites of $T$. gondii ME49 strain, 4 weeks after the last immunization ( $n=9$ animals per group). Comparisons of differences between experimental group pEGFP-SOD and control groups (Blank control, PBS or pEGFP-C1) were significant $(p<0.05)$ especially investigated in the last few years [25-28]. In the present study, a DNA vaccine encoding $T$. gondii SOD was constructed and the SOD protein was expressed in HEK 293 T cells in vitro. The SOD was identified to play a role in affecting the intracellular growth of both bradyzoite and tachyzoite forms in T. gondii. Our present results exhibited that the DNA vaccine encoding $T$. gondii SOD could partially protect the challenged BALB/c mice with a lethal dose of $T$. gondii ME49 strain through inducing highly significant cellular and humoral immune responses, illustrating SOD can be an alternative vaccine antigen for preventing $T$. gondii infection.

Given the features of $T$. gondii being an intracellular parasite, specific cellular immune response, particularly, a specific $\mathrm{T}$ lymphocytes activation $\left(\mathrm{CD}^{+} \mathrm{T}\right.$ cells and $\mathrm{CD}^{+} \mathrm{T}$ cells) can play a vital role in the alleviation or control of spreading and development of $T$. gondii in infection [29]. Both $\mathrm{CD}^{+} \mathrm{T}$ cells and $\mathrm{CD}^{+} \mathrm{T}$ cells are well-characterized lymphocytes that respond to intracellular pathogens. The $\mathrm{CD} 4^{+}$is one of the surface markers of $\mathrm{T}$ helper $\left(\mathrm{T}_{\mathrm{H}}\right)$ cells that participate in the adaptive immune responses, while $\mathrm{CD}^{+}{ }^{+}$is expressed on cytotoxic $\mathrm{T}$ cells (CTLs), which are classified as a pre-defined cytotoxic role in the immune system [30]. $\mathrm{CD}^{+} \mathrm{T}$ cells appear critical in limiting pathogen further growth in the early stage of intracellular infection, whereas $\mathrm{CD}^{+} \mathrm{T}$ cells are particularly important in the later stage of infection [30]. IFN- $\gamma$ produced by Toxoplasma-specific CD $4^{+}$ and $\mathrm{CD}^{+} \mathrm{T}$ cells further contributes to the host defense against $T$. gondii infection [31]. The production of IFN- $\gamma$ in response to intracellular microbial exposure is critical to indicate the partial immunity against $T$. gondii by controlling the growth of the parasite in the acute phase [32]. IFN- $\gamma$ also plays a vital role in promoting naive $\mathrm{CD}^{+}{ }^{+} \mathrm{T}$ cells (Th0 cells) to differentiate into Th1 cells, while restraining from Th2 cell differentiation [33]. IL-4 and IL-10 that are produced by CD $4{ }^{+}$Th2 cells are two anti-inflammatory cytokines, which have a significant function to balance and alleviate the harmful inflammatory effect, and favor a Th1 immune response for the control of T. gondii infection [34]. In the present study, the mice immunized with pEGFP-SOD were observed to produce higher percentage of $\mathrm{CD}^{+}$and $\mathrm{CD} 4^{+} \mathrm{T}$ cells, especially the $\mathrm{CD}^{+} \mathrm{T}$ cells $(p<0.05)$. Additionally, higher levels of IFN- $\gamma$ were induced in mice from pEGFP-SOD group compared to the control groups. In contrast, the SOD DNA vaccine failed to stimulate the production of IL-4 and IL-10 $(p>0.05)$. The data above demonstrated that the immunized mice with pEGFPSOD vaccine could resist $T$. gondii infection through eliciting Th1 immune response characterized by high levels of IFN- $\gamma$, and low levels of IL- 4 or IL- 10 .

Along with cellular immune responses, humoral immunity with specific antibodies also plays an important 
role in controlling T. gondii infection [35]. The specific antibody against $T$. gondii has been confirmed to mainly interfere in the attachment between the parasite and the host cell receptors, and to be involved in the process of killing intracellular parasites by macrophages [36]. In the present study, the results showed that total IgG antibody was induced higher in the experimental group compared with the control groups. Additionally, the IgG subclass (IgG1 and IgG2a) results in the experimental group revealed that IgG2a has an obvious advantage over IgG1. Generally, the production of IgG1 is associated with Th2 type immunity, while IgG2a is closely related to Th1 response [37]. Thus, the high levels of IgG2a from the immunized mice serum in this study evinced that the SOD DNA vaccine could produce Th1 immune response.

Similarly, SOD vaccine has an ability to stimulate protective immune responses against other parasites $[38,39]$. For example, the pVAX1-SOD DNA partially protected $\mathrm{BALB} / \mathrm{c}$ mice from the challenge with Leishmania amazonensis, which was associated with a mixed immune response including the production of IFN$\gamma$ and IL-4 from $\mathrm{CD}_{4}^{+}$and $\mathrm{CD} 8^{+} \mathrm{T}$ lymphocytes [38]. In addition, the rBmEC-SOD vaccine could excite typical Th1 response against infective larvae and microfilariae in jirds with filarial infection [39]. In agreement with those studies, our investigate proved that the DNA vaccine encoding $T$. gondii SOD triggered strong humoral and cellular immune responses, and aroused partial protective immunity against acute $T$. gondii ME49 strain infection in BALB/c mice. From the above the SOD may be a potentially useful alternative to be developed as an effective vaccine for parasite.

In our previous study [20, 21], the protective efficacy of DNA vaccine was evaluated against $T$. gondii $\mathrm{RH}$ (type I) strain. However, RH strain is highly virulent pathogenic and lethal to mice, whereas Type II strain is the predominant lineage causing toxoplasmosis in humans [3]. Thus, in this study, we intentionally chose $1 \times 10^{3}$ tachyzoites of moderate virulent T. gondii ME49 strain, as one of type II, to investigate the immune protection of SOD DNA vaccine against challenge acute infection. The survival assay demonstrated that the immunization with SOD DNA vaccine significantly prolonged the survival time of challenged mice in comparison with those of control groups, which indicated that the immunization with SOD DNA vaccine was able to produce a certain level of effective immunity against acute $T$. gondii infection in BALB/c mice model. Unfortunately, the symptoms of the challenged mice in later infection stage and the final death confirmed that the SOD DNA vaccine elicited incomplete protective efficacy, which could be largely attributed to the inappropriate immunization strategy, challenge protocol, and insufficiency evaluation criterion. In addition, mouse strains including the age, gender and weight, parasite strains including the dosage, route and stage, are important factors that might hinder the accuracy of experimental results. Nevertheless, these issues should be considered and explored in the future study.

\section{Conclusion}

In brief, our study demonstrated that the DNA vaccine encoding SOD could trigger strong humoral and cellular immune responses, and elicit partial protective immunity against acute $T$. gondii infection in the murine model. Although SOD elicited only partial protection against acute toxoplasmosis, SOD could be a potential vaccine candidate for further investigations in evaluating the immunogenicity and protective potency of SOD based vaccines against toxoplasmosis.

\section{Abbreviations \\ Con A: concanavalin A; ELISA: Enzyme-linked immunosorbent assay; \\ SOD: Superoxide dismutase; STAg: Soluble tachyzoite antigens; \\ TgSOD: Superoxide dismutase of T. gondii}

\section{Acknowledgements}

The authors wish to thank Dr. Quan Liu and Dr. Qijun Chen for kindly providing the ME49 strain of Toxoplasma gondii and Dr. Fangming Xiu for his proofreading and correction of the manuscript.

\section{Funding}

This study was financially supported by National Natural Science Foundation of China (Grant No. 81471974).

\section{Availability of data and materials}

All data supporting the findings are within the manuscript.

\section{Authors' contributions}

$\mathrm{HZ}$ conceived and designed the study, and $\mathrm{HZ}$ critically revised the manuscript; $Y L, A C$, and $Y W L$ performed experiments; $X L, H C$ and $S H$ analyzed the data and participated the first manuscript draft. All authors have read and approved the final manuscript.

\section{Competing interests}

The authors declare that they have no competing interests.

\section{Consent for publication \\ Not applicable.}

\section{Ethics approval and consent to participate \\ All animal care procedures were conducted in strict accordance with the Animal Ethics Procedures and Guidelines of the People's Republic of China. The study was approved by the Institutional Animal Care and Use Committee of Shandong University under Contract LL2015-02.}

\section{Publisher's Note}

Springer Nature remains neutral with regard to jurisdictional claims in published maps and institutional affiliations.

\section{Author details}

'Department of Parasitology, School of Medicine, Shandong University, Jinan, Shandong Province, People's Republic of China. ${ }^{2}$ Department of Medicinal Chemistry, School of Pharmaceutical Sciences, Shandong University, Jinan, Shandong Province, People's Republic of China. ${ }^{3}$ Present address Department of Clinical Laboratory, The People's Hospital of Rizhao, Rizhao, Shandong Province, People's Republic of China. 
Received: 2 November 2016 Accepted: 30 May 2017

Published online: 07 June 2017

\section{References}

1. Montoya JG, Liesenfeld O. Toxoplasmosis. Lancet. 2004;363:1965-76.

2. Tenter AM, Heckeroth AR, Weiss LM. Toxoplasma gondii: from animals to humans. Int J Parasitol. 2000:30:1217-58

3. Weiss LM, Dubey JP. Toxoplasmosis: a history of clinical observations. Int J Parasitol. 2009;39:895-901.

4. Elmore SA, Jones JL, Conrad PA, Patton S, Lindsay DS, Dubey JP. Toxoplasma gondii: epidemiology, feline clinical aspects, and prevention. Trends Parasitol. 2010;26:190-6

5. Dubey J, Hill D, Jones J, Hightower A, Kirkland E, Roberts J, et al. Prevalence of viable Toxoplasma gondii in beef, chicken, and pork from retail meat stores in the United States: risk assessment to consumers. J Parasitol. 2005; 91:1082-93.

6. Hill DE, Dubey JP. Toxoplasma gondii prevalence in farm animals in the United States. Int J Parasitol. 2013:43:107-13.

7. Cenci-Goga BT, Rossitto PV, Sechi P, McCrindle CM, Cullor JS. Toxoplasma in animals, food, and humans: an old parasite of new concern. Foodborne Pathog Dis. 2011:8:751-62.

8. Guo M, Dubey JP, Hill D, Buchanan RL, Gamble HR, Jones JL, et al. Prevalence and risk factors for Toxoplasma gondii infection in meat animals and meat products destined for human consumption. J Food Prot. 2015;78:457-76.

9. Hiszczyńska-Sawicka E, Gatkowska JM, Grzybowski MM, Długońska H. Veterinary vaccines against toxoplasmosis. Parasitology. 2014;141:1365-78.

10. Zhang NZ, Chen J, Wang M, Petersen E, Zhu XQ. Vaccines against Toxoplasma gondii: new developments and perspectives. Expert Rev Vaccines. 2013:12: 1287-99.

11. Blake DP, Billington KJ, Copestake SL, Oakes RD, Quail MA, Wan KL, et al. Genetic mapping identifies novel highly protective antigens for an apicomplexan parasite. PLoS Pathog. 2011;7:e1001279.

12. Kur J, Holec-Gasior L, Hiszczyńska-Sawicka E. Current status of toxoplasmosis vaccine development. Expert Rev Vaccines. 2009;8:791-808.

13. Buxton D, Innes EA. A commercial vaccine for ovine toxoplasmosis. Parasitology. 1995;110(Suppl):S11-6.

14. Laddy DJ, Weiner DB. From plasmids to protection: a review of DNA vaccines against infectious diseases. Int Rev Immunol. 2006;25:99-123.

15. Henriquez FL, Woods S, Cong H, McLeod R, Roberts CW. Immunogenetics of Toxoplasma gondii informs vaccine design. Trends Parasitol. 2010;26:550-5.

16. Miller AF. Superoxide dismutases: ancient enzymes and new insights. FEBS Lett. 2012;586:585-95.

17. Fukai T, Ushio-Fukai M. Superoxide dismutases: role in redox signaling, vascular function, and diseases. Antioxid Redox Signal. 2011;15:1583-606.

18. Odberg-Ferragut C, Renault JP, Viscogliosi E, Toursel C, Briche I, Engels A, et al. Molecular cloning, expression analysis and iron metal cofactor characterisation of a superoxide dismutase from Toxoplasma gondii. Mol Biochem Parasitol. 2000;106:121-9.

19. Wang S, Cao A, Li X, Zhao Q, Liu Y, Cong H, et al. Sequence variation in Superoxide dismutase Gene of Toxoplasma gondii among various isolates from different hosts and geographical regions. Korean J Parasitol. 2015;53: 253-8.

20. Zhou H, Min J, Zhao Q, Gu Q, Cong H, Li Y, et al. Protective immune response against Toxoplasma gondii elicited by a recombinant DNA vaccine with a novel genetic adjuvant. Vaccine. 2012;30:1800-6.

21. Liu Q, Wang F, Wang G, Zhao Q, Min J, Wang S, et al. Toxoplasma gondii: immune response and protective efficacy induced by ROP16/GRA7 multicomponent DNA vaccine with a genetic adjuvant B7-2. Hum Vaccin Immunother. 2014;10:184-91.

22. Gurunathan S, Klinman DM, Seder RA. DNA vaccines: immunology, application, and optimization. Annu Rev Immunol. 2000;18:927-74

23. Gurunathan $S$, Wu $C Y$, Freidag BL, Seder RA. DNA vaccines: a key for inducing long-term cellular immunity. Curr Opin Immunol. 2000;12:442-7.

24. Verma R, Khanna P. Development of Toxoplasma gondii vaccine: a global challenge. Hum Vaccin Immunother. 2013:9:291-3.

25. Chen J, Huang SY, Li ZY, Yuan ZG, Zhou DH, Petersen E, et al. Protective immunity induced by a DNA vaccine expressing elF4A of Toxoplasma gondi against acute toxoplasmosis in mice. Vaccine. 2013;31:1734-9.

26. Hassan IA, Wang $S$, Xu L, Yan $R$, Song $X$, Li X. DNA vaccination with a gene encoding Toxoplasma gondii Deoxyribose phosphate Aldolase (TgDPA) induces partial protective immunity against lethal challenge in mice. Parasit Vectors. 2014:7:431.

27. Xu Y, Zhang NZ, Tan QD, Chen J, Lu J, Zhu XQ, et al. Evaluation of immunoefficacy of a novel DNA vaccine encoding Toxoplasma gondii rhoptry protein 38 (TgROP38) against chronic toxoplasmosis in a murine model. BMC Infect Dis. 2014;14:525.

28. Yuan ZG, Ren D, Zhou DH, Zhang XX, Petersen E, Li XZ, et al. Evaluation of protective effect of pVAX-TgMIC13 plasmid against acute and chronic Toxoplasma gondii infection in a murine model. Vaccine. 2013;31:3135-9.

29. Dupont CD, Christian DA, Selleck EM, Pepper M, Leney-Greene M, Harms Pritchard $\mathrm{G}$, et al. Parasite fate and involvement of infected cells in the induction of CD4+ and CD8+ T cell responses to Toxoplasma gondii. PLoS Pathog. 2014;10(4):e1004047.

30. Kemball CC, Pack CD, Guay HM, Li ZN, Steinhauer DA, Lukacher AE, et al. The antiviral CD8+ $T$ cell response is differentially dependent on CD4+ $T$ cell help over the course of persistent infection. J Immunol. 2007;179:1113-21.

31. Dupont CD, Christian DA, Hunter CA. Immune response and immunopathology during toxoplasmosis. Semin Immunopathol. 2012;34:793-813.

32. Suzuki Y, Sa Q, Gehman M, Ochiai E. Interferon-gamma- and perforin-mediated immune responses for resistance against Toxoplasma gondii in the brain. Expert Rev Mol Med. 2011;13:e31.

33. Schroder K, Hertzog PJ, Ravasi T, Hume DA. Interferon-gamma: an overview of signals, mechanisms and functions. J Leukoc Biol. 2004;75:163-89.

34. Gigley JP, Fox BA, Bzik DJ. Cell-mediated immunity to Toxoplasma gondi develops primarily by local Th1 host immune responses in the absence of parasite replication. J Immunol. 2009;182:1069-78.

35. Johnson LL, Lanthier P, Hoffman J, Chen W. Vaccination protects B celldeficient mice against an oral challenge with mildly virulent Toxoplasma gondii. Vaccine. 2004;22:4054-61.

36. Kang H, Remington JS, Suzuki Y. Decreased resistance of B cell-deficient mice to infection with Toxoplasma gondii despite unimpaired expression of IFN-gamma, TNF-alpha, and inducible nitric oxide synthase. J Immunol. 2000;164:2629-34

37. Germann T, Bongartz M, Dlugonska H, Hess H, Schmitt E, Kolbe L, et al. Interleukin-12 profoundly up-regulates the synthesis of antigen-specific complement-fixing lgG2a, lgG2b and lgG3 antibody subclasses in vivo. Eur J Immunol. 1995:25:823-9.

38. Campos BL, Silva TN, Ribeiro SP, Carvalho K, Kallás EG, Laurenti MD, et al. Analysis of iron superoxide dismutase-encoding DNA vaccine on the evolution of the Leishmania amazonensis experimental infection. Parasite Immunol. 2015;37:407-16.

39. Dabir S, Dabir P, Goswami K, Reddy MV. Prophylactic evaluation of recombinant extracellular superoxide dismutase of Brugia malayi in jird model. Vaccine. 2008;26: 3705-10.

\section{Submit your next manuscript to BioMed Central and we will help you at every step:}

- We accept pre-submission inquiries

- Our selector tool helps you to find the most relevant journal

- We provide round the clock customer support

- Convenient online submission

- Thorough peer review

- Inclusion in PubMed and all major indexing services

- Maximum visibility for your research

Submit your manuscript at www.biomedcentral.com/submit 